\title{
Commentary: Reassessing efficacy of treatment strategies for secondary mitral regurgitation-Combining pathoanatomic and pathophysiologic perspectives
}

\author{
Gabriel S. Aldea, MD
}

\author{
From the Department of Cardiothoracic Surgery, University of Washington Medical School, Seattle, Wash. \\ Disclosures: Author has nothing to disclose with regard to commercial support. \\ Received for publication Jan 21, 2019; accepted for publication Jan 22, 2019; available ahead of print March 7, \\ 2019. \\ Address for reprints: Gabriel S. Aldea, MD, Cardiothoracic Surgery, University of Washington Medical School, \\ Box 356310, 1959 NE Pacific St, Seattle, WA 98195-6310 (E-mail: aldea@uw.edu). \\ J Thorac Cardiovasc Surg 2019;158:84-5 \\ $0022-5223 / \$ 36.00$ \\ Copyright (c) 2019 by The American Association for Thoracic Surgery \\ https://doi.org/10.1016/j.jtcvs.2019.01.082
}

Secondary mitral regurgitation (SMR) is a heterogeneous spectrum of disease processes that result from abnormal systolic tethering and global or regional derangements of size and function of the left ventricle (LV) that manifest with significant regurgitant mitral flow despite the presence of normal valve leaflets and chordae tendineae. Complexities of variable clinical presentations, lack of adherence to and implementation of guideline-directed optimal medical and synchronization therapies (GDMT), and imprecise echocardiographic imaging and quantification are increasingly recognized.

Prognoses of patients with severe SMR and depressed LV function randomly assigned to the GDMT arms have remained sobering, with heart failure hospitalization rate and mortality of $49 \%$ and $24 \%$, respectively, at 12 months in the Multicentre Study of Percutaneous Mitral Valve Repair MitraClip Device in Patients With Severe Secondary Mitral Regurgitation (MITRA-FR) study ${ }^{1}$ and $68 \%$ and $46 \%$, respectively at 24 months for the Cardiovascular Outcomes Assessment of the MitraClip Percutaneous Therapy for Heart Failure Patients With Functional Mitral Regurgitation (COAPT) study. ${ }^{2}$ Although interventions can be undertaken with reasonably low and acceptable risks, it is disappointing but not surprising that previous surgical therapies directed at the mitral valve with no enduring effect on the abnormal LV had no effect on survival, with high recurrence rate for mitral valve repair and high mortality for mitral valve replacement (despite chordal preservation). ${ }^{3-5}$ These efforts mirror disappointing attempts to add LV restoration interventions to the coronary revascularization in the management of ischemic heart disease with global, nonaneurysmal dilated LV cardiomyopathy. ${ }^{6}$ Retrospective analyses of the Pivotal Study of a Percutaneous Mitral Valve Repair System (EVEREST II) trial demonstrated improved clinical outcomes and symptoms despite a statistically significant but only modest reduction in LV volumes (-8.0 mL) when MitraClip (Abbott Vascular Inc, Santa

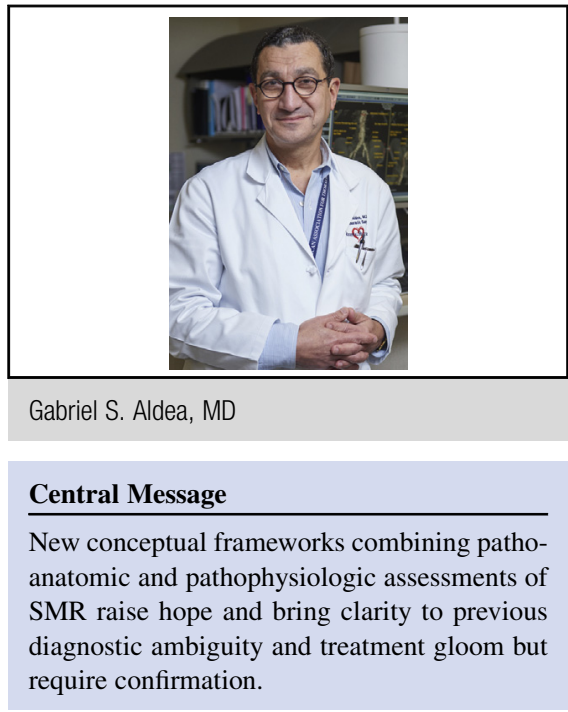

See Editorial page 76.
Clara, Calif) transcatheter therapy was applied to a subset of patients with $\mathrm{SMR}^{7}$ and prompted the MITRA-FR ${ }^{1}$ and COAPT $^{2}$ prospective, randomized trials. These trials focused on SMR and compared MitraClip therapy with GDMT. Their results were unexpectedly contradictory. MITRA-FR is considered to represent a less proscriptive "real-world" approach, whereas the COAPT had a more structured, discriminating methodology to SMR, as noted by much stricter inclusion criteria, strict adjudication, and higher screening failure rate $(58 \%)$. Two new conceptual approaches attempt to resolve and unify these discrepant outcomes, recognizing that these studies may have been applied to different patient populations. The article in this issue of the Journal by Badhwar and colleagues ${ }^{8}$ adds a significant and needed dimension to our current quantification and description of SMR by systematically grading pathoanatomic features, such as the degree of mitral annular dilatation, ejection fraction, and leaflet tethering and papillary muscle displacement in an attempt to assign more effective and targeted treatment options to more advanced clinical presentations. Notably missing is analyses of how patients with SMR are distributed across these pathoanatomic subcategories, which would enable better understanding of their specificity or possible overlap. An even more 
significant conceptual framework and breakthrough is the recognition of 2 pathophysiologic factors: (1) Mitral regurgitation and increased effective regurgitant volume area are difficult to quantify accurately and are common with progressive LV dilatation, increased LV end-diastolic volume, and LV dysfunction. Current guidelines thus may overstate the physiologic significance of mitral regurgitation in these settings. (2) Rather than absolute measurements, indexing or normalizing mitral regurgitation and effective regurgitant volume area as "proportionate" or "disproportionate" to LV end-diastolic volume may better discriminate subsets of patients who will benefit from interventions for SMR. ${ }^{9}$ Patients with "disproportionate" mitral regurgitation were much more common in the COAPT trial than in the MITRA-FR trial. These patients responded to MitraClip intervention with dramatic decreases in heart failure hospitalizations (hazard ratio, $0.53 ; P<.001$; number needed to treat, 3) and improved all-cause mortality (hazard ratio, $0.62 ; P<.001$; number needed to treat, 6 ). ${ }^{2}$

There is an increased appreciation of the complexities and clinical heterogeneity of SMR, with an emphasis on initial GDMT to stabilize patient condition, rather than proceeding directly with emergency salvage interventions. Once a patient's condition has been stabilized, a thoughtful and detailed assessment of pathoanatomic manifestations of SMR that include degree of mitral annular dilation, LV ejection fraction, leaflet tethering, and pathophysiological categorization of effective regurgitant volume area as an index LV end-diastolic volume with identification of "disproportionate" mitral regurgitation can significantly focus treatment options with the aim of enhancing their effectiveness. It is important to add a note of caution that although initially successful, previous surgical therapies directed to mitral leaflets alone (such as the edge-to-edge repair that is the conceptual basis of MitraClip therapy) without secondary interventions to stabilize or reduce the mitral valve annulus or displaced papillary muscles, particularly when applied to SMR, may be inadequate with time if LV size and volume continue to enlarge and tethering continues unabated. ${ }^{10-12}$ The need for longer-term follow-up for these emerging therapies is evident. As with ongoing studies that aim to assess earlier therapy for aortic stenosis in patients with more limited cardiac reserve, ${ }^{13}$ as transcatheter mitral valve technologies continue to mature, trials designed to study possible effects of earlier interventions for "disproportionate" SMR in asyet undefined at-risk patient populations are also needed for thoughtful evaluation of whether the progression of LV pathology can be mitigated or ameliorated before a threshold of irreversible LV size and dysfunction is reached.

In conclusion, these new conceptual frameworks and paradigms combining pathoanatomic and pathophysiologic assessments of SMR raise hope and bring more clarity to a sea of previous diagnostic ambiguity and treatment gloom, but they require confirmation.

\section{References}

1. Obadia JF, Messika-Zeitoun D, Leurent G, Iung B, Bonnet G, Piriou N, et al. Percutaneous repair or medical treatment for secondary mitral regurgitation. N Engl J Med. 2018;379:2297-306.

2. Stone GW, Lindenfeld J, Abraham WT, Kar S, Lim DS, Mishell JM, et al COAPT Investigators. Transcatheter mitral-valve repair in patients with heart failure. N Engl J Med. 2018;379:2307-18.

3. Smith PK, Puskas JD, Ascheim DD, Voisine P, Gelijns AC, Moskowitz AJ, et al; Cardiothoracic Surgical Trials Network Investigators. Surgical treatment of moderate ischemic mitral regurgitation. N Engl J Med. 2014;371:2178-88.

4. Acker MA, Parides MK, Perrault LP, Moskowitz AJ, Gelijns AC, Voisine P, et al; CTSN. Mitral valve repair versus replacement for severe ischemic mitral regurgitation. N Engl J Med. 2014;370:23-32.

5. Wu AH, Aaronson KD, Bolling SF, Pagani FD, Welch K, Koelling TM. Impact of mitral valve annuloplasty on mortality risk in patients with mitral regurgitation and left ventricular systolic dysfunction. J Am Coll Cardiol. 2005;45:381-7.

6. Prior DL, Stevens SR, Holly TA, Krejca M, Paraforos A, Pohost GM, et al; STICH Trial Investigators. Regional left ventricular function does not predict survival in ischaemic cardiomyopathy after cardiac surgery. Heart. 2017;103: 1359-67.

7. Ailawadi G, Lim DS, Mack MJ, Trento A, Kar S, Grayburn PA, et al; EVEREST II Investigators. One-year outcomes after MitraClip for functional mitral regurgitation. Circulation. 2019;139:37-47.

8. Badhwar V, Alkhouli M, Mack MJ, Thourani VH, Ailawadi G. A pathoanatomic approach to secondary mitral regurgitation: evaluating the evidence. $J$ Thorac Cardiovasc Surg. 2019;158:76-81.

9. Grayburn PA, Sannino A, Packer M. Proportionate and disproportionate functional mitral regurgitation: a new conceptual framework that reconciles the results of MITRA-FR and COAPT trials. Int J Cardiol Heart Vasc. 2018;22:18-9.

10. De Bonis M, Lapenna E, Pozzoli A, Giacomini A, Alfieri O. Edge-to-edge surgical mitral valve repair in the era of MitraClip: what if the annuloplasty ring is missed? Curr Opin Cardiol. 2015;30:155-60.

11. Kron IL, Hung J, Overbey JR, Bouchard D, Gelijns AC, Moskowitz AJ, et al. Predicting recurrent mitral regurgitation after mitral valve repair for severe ischemic mitral regurgitation. J Thorac Cardiovasc Surg. 2015;149:752-61.e1.

12. Hvass U, Joudinaud T. The papillary muscle sling for ischemic mitral regurgitation. J Thorac Cardiovasc Surg. 2010;139:418-23.

13. Evaluation of Transcatheter Aortic Valve Replacement Compared to SurveilLance for Patients With AsYmptomatic Severe Aortic Stenosis (EARLY TAVR). Available at: https://clinicaltrials.gov/ct2/show/NCT03042104. Accessed February 15, 2019. 